at the anastomosis between the ITA and the saphenous vein elongation.

The recycling of ITA grafts can be performed in only a selected redo $\mathrm{CABG}$ population, ${ }^{3}$ when the ITA is patent but stenotic in the perianastomotic area, when there is a stenosis in the coronary artery distal to the anastomosis, and when an interventional cardiologic approach is not feasible. Preoperative selective angiography of the used ITA is helpful to exclude proximal stenosis, to locate its relationship, and to provide anatomic details that may suggest this possible alternative approach during redo $\mathrm{CABG}$ surgery.

In conclusion, our limited experience confirmed that the recycling of ITA grafts in redo CABG can produce satisfactory outcomes in selected patients even at long-term follow-up.

\section{References}

1. Burfeind WR Jr, Glower DD, Wechsler AS, Tuttle RH, Shaw LK, Harrel FE Jr, et al. Single versus multiple internal mammary artery grafting for coronary artery bypass: 15 year follow-up of a clinical practice trial. Circulation. 2004;110(Suppl):II27-35.

2. Cameron A, Davis KB, Green G, Schaff HV. Coronary bypass surgery with internal-thoracic artery grafts: effects on survival over a 15 -year period. N Engl J Med. 1996;334:216-9.

3. Noyez L, Lacquet LK. Recycling of the internal mammary artery in coronary reoperation. Ann Thorac Surg. 1993;55:597-9.

4. Antona C, Parolari A, Zanobini M, Arena V, Biglioli P. Midterm angiographic study of five recycled mammary arteries during four coronary redos. Ann Thorac Surg. 1996;61:702-5.

5. Noirhomme PH, Underwood MJ, El Khoury GA, Glineur D, Elias B, d'Udekem Y, et al. Recycling of arterial grafts during reoperative coronary artery operations. Ann Thorac Surg. 1999;67:641-4.

\title{
Complete vascular ring presenting in adulthood: An unusual management dilemma
}

\author{
Edward J. Hickey, MD, Aftab Khan, MRCS, David Anderson, FRCS, and Loic Lang-Lazdunski, FRCS, London, United \\ Kingdom
}

\section{Clinical Summary}

Patient 1. An otherwise fit 47-year-old woman presented with progressive dyspnea and wheeze on minimal exertion over several years. After a negligible response to bronchodilators, bronchoscopy demonstrated extrinsic compression causing midtracheal collapse. A computed tomographic (CT) scan indicated a right-sided aortic arch with a Kommerell diverticulum and a retroesophageal left subclavian artery (Figure 1). She underwent a left posterior lateral thoracotomy through the fifth intercostal space. The ligamentum arteriosum (completing the type 3 ring) appeared to be the principal cause of tracheal compromise and was divided to achieve complete decompression. Recovery was uneventful, and she is symptom-free 12 months later.

Patient 2. A 37-year-old female nonsmoker described limited exercise tolerance and exertional wheeze since childhood. Medical attention was sought only after significant symptom exacerbation during pregnancy. Physical examination was unremarkable, but the flow-volume loop suggested large airway obstruction. Flexible bronchoscopy revealed erythema and extrinsic compression imme-

From the Department of Thoracic Surgery, Guy's Hospital, King's College London, London, United Kingdom.

Received for publication Jan 3, 2007; accepted for publication Jan 31, 2007.

Address for reprints: Loic Lang-Lazdunski, MD, PhD, FRCS, Department of Thoracic Surgery, Guy's Hospital, King's College Hospital, St Thomas St, London SE1 9RT, United Kingdom (E-mail: loic.lang-lazdunski@ gstt.nhs.uk).

J Thorac Cardiovasc Surg 2007;134:235-6

$0022-5223 / \$ 32.00$

Copyright $\odot 2007$ by The American Association for Thoracic Surgery

doi:10.1016/j.jtcvs.2007.01.083 diately proximal to the carina in the anteroposterior plane. In addition, the origin of the right upper lobe bronchus arose directly from the carina. CT suggested these bronchoscopic findings to be attributable to a right aortic arch with an aberrant retroesophageal left subclavian artery arising from a Kommerell diverticulum. A decision was made to intervene surgically. At the fourth-space left thoracotomy, the complete vascular ring (type 3 ) was confirmed by the presence of the left ductal remnant, which was divided to allow distraction of the diverticulum away from the esophagus. Despite initial improvement, she relapsed 5 years later. A 3-dimensional $\mathrm{CT}$ reconstruction demonstrated the diverticulum compressing the trachea posteriorly. Right thoracotomy was performed to approach the aberrant left subclavian artery, the origin of which was divided and oversewn. The Kommerell diverticulum was then resected, and primary repair of the aorta was undertaken. Tracheal decompression was satisfactory, and the patient is symptom-free 12 months later.

\section{Discussion}

The right aortic arch can form a complete vascular ring through the presence of a ligamentum arteriosum (or persistent duct). In these circumstances, tracheoesophageal compression might typically occur from the embarrassment of either the ligamentum or a Kommerell diverticulum, an aortic pouch from which the aberrant subclavian artery arises. The anomaly typically becomes evident in infancy and requires, at minimum, the surgical release of the ligamentum. Recurrence occurs in a small proportion of cases and has been attributed to aneurysmal dilatation of the Kommerell diverticula, which usually require subsequent resection. ${ }^{1}$

Primary presentations in adulthood are extremely unusual but might masquerade as chronic asthma ${ }^{2}$ until identification, occasionally as late as the seventh decade. ${ }^{3}$ This report highlights 2 


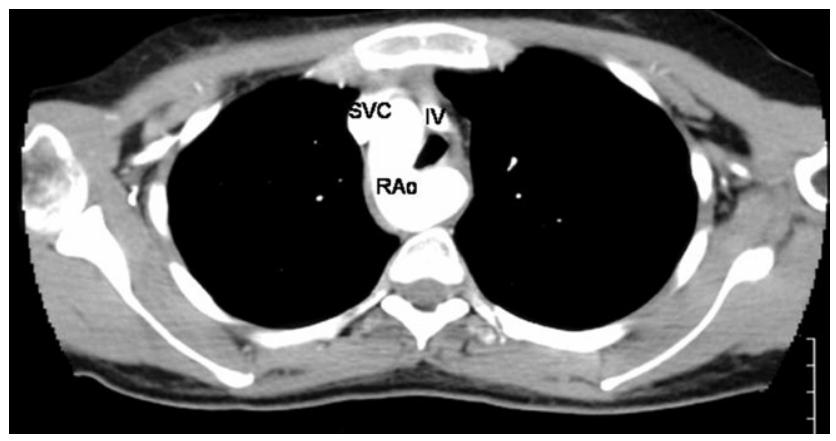

Figure 1. Axial computed tomographic scan through T4 showing a right-sided aortic arch (RAo) compressing the anterolateral aspect of the trachea. The aberrant left subclavian artery is not visible on this scan but arose from the Kommerell diverticulum. $I V C$, Inferior vena cava; IV, innominate vein.

contrasting scenarios: (1) a new diagnosis in the fifth decade after having tolerated symptoms for many years and (2) an adult with a late recurrence of symptoms after ligamentum division 5 years previously.

No ideal management strategy has yet been clarified for the rare symptomatic adults. A confounding issue might be the reluctance of patients with insidious progression of mild symptoms to subject themselves to thoracotomy and reconstruction of major vascular components with its inherent risk. Consequently, we adopted a more conservative approach by dividing only the ligamentum in patient 1 , with good intraoperative and symptomatic results. However, our experience with patient 2 indicates that, as in children, a late hazard phase exists for the development of recurrence. Performing simple aortopexy or adhesiolysis might seem attractive; however, the pediatric experience of Backer and colleagues ${ }^{4}$ with late reintervention implies that formal resection of the Kommerell diverticulum is necessary to achieve definitive relief. Therefore we would concur that recurrent symptoms should dictate formal resection or reconstruction of the contributing vascular components. In infancy this might require reimplantation of aberrant vessels. We chose to divide and oversew the aberrant left (nondominant) subclavian artery. The patient has experienced no ischemic left arm symptoms as a result of this.

An important difference between the pediatric and adult management strategies is the surgical approach, which is typically through a median sternotomy in children. By contrast, access to the posterior arch and aberrant vessels is especially difficult in adults, even through the use of deep hypothermic circulatory arrest. We therefore chose to approach the ligamentum through a left thoracotomy and subsequent vascular reconstruction through a right thoracotomy if necessary.

The use of self-expanding tracheal stents is inadvisable in benign tracheal conditions because of the propensity for granulation and stricture development. ${ }^{5}$ Instead, our overall proposed strategy is to adopt a staged approach: undertake primary ligamentum division and tracheal release through a left thoracotomy in the first instance with careful assessment of the resulting tracheal expansion. If complete release is evident, we suggest it is reasonable to defer more hazardous vascular reconstruction for the patients who experience symptomatic recurrence, which can occur many years later and can be approached through a right thoracotomy. If tracheal embarrassment is evident despite ligamentum release, formal Kommerell resection with division/reimplantation of aberrant vessels should be performed through a right thoracotomy 6 weeks later. ${ }^{3}$

\section{References}

1. Backer CL, Hillman N, Mavroudis C, Holinger LD. Resection of Kommerell's diverticulum and left subclavian artery transfer for recurrent symptoms after vascular ring division. Eur J Cardiothorac Surg. 2002;22:64-9.

2. Morel V, Corbineau H, Lecoz A, Verhoye JP, Heautot JF, Bassen R, et al. Two cases of "asthma" revealing a diverticulum of Kommerell. Respiration. 2002;69:456-60.

3. Greiner A, Perkmann R, Rieger M, Neuhauser B, Fraedrich G. Vascular ring causing tracheal compression in an adult patient. Ann Thorac Surg. 2003;75:1959-60.

4. Backer CL, Mavroudis C, Rigsby CK, Holinger LD. Trends in vascular ring surgery. J Thorac Cardiovasc Surg. 2005;129:1339-47.

5. Gaissert HA, Grillo HC, Wright CD, Donahue DM, Wain JC, Mathisen DJ. Complication of benign tracheobronchial strictures by self-expanding metal stents. J Thorac Cardiovasc Surg. 2003;126: $744-7$. 